International Journal of Innovative Engineering Applications

Journal homepage: $\underline{\text { https://dergipark.org.tr/ijiea }}$

\title{
PREDICTION OF BLAST-INDUCED GROUND VIBRATION WITH ANN AND PREDICTION PERFORMANCE
}

\author{
Serdar Ercins ${ }^{* 1}$ (D) \\ ${ }^{I}$ Sivas Cumhuriyet University, Sivas Technical Sciences Vocational School, Mining Dept., Sivas-Turkey
}

\begin{abstract}
Original scientific paper

In this study, ground vibrations caused by blasting applications in a quarry were recorded and these values were evaluated and estimated by using an artificial neural network (ANN) model. Of the 28 vibration data measured, 20 were used for ANN training, 4 for validation and the remaining 4 for testing. In the model, peak particle velocity (PPV) was used as the output parameter, and the maximum explosive amount per delay and scaled distance were used as input parameters. In addition, MAPE, RMSE and $\mathrm{R}^{2}$ performance criteria were calculated from the realized, predicted by ANN and PPV values obtained from the field equation. The maximum amount of explosives used per delay and the sensitivity analysis of the scaled distance on the highest particle velocity were also determined. As a result, when the vibration data calculated from the field equation and estimated from the ANN model were compared with the realized vibration data, it was seen that the values obtained by the ANN model had a higher correlation.
\end{abstract}

Keywords: Artificial neural network, vibration, blasting, quarry, sensitivity analysis, MAPE, RMSE, $R^{2}$.

\section{PATLAMA KAYNAKLI YER TITREŞIMININ YSA ILE TAHMINI VE TAHMIN PERFORMANSI}

\section{$\ddot{O}_{z e t}$}

Orijinal bilimsel makale

$\mathrm{Bu}$ çalışmada bir taş ocağında gerçekleştirilen patlatma uygulamalarından kaynaklanan yer titreşimleri kaydedilmiş ve bu değerler yapay sinir ağı (YSA) modeli kullanılarak değerlendirilmiş ve tahmin edilmiştir. Ölçümü alınan 28 titreşim verisinin 20 tanesi YSA'nın eğitimi, 4'ü doğrulama ve geriye kalan 4'ü de test için kullanılmıştır. Modelde çıktı parametresi olarak PPV, girdi parametresi olarak ise gecikme başına en fazla patlayıcı miktarı ve ölçekli mesafe kullanılmıştır. Ayrıca MAPE, RMSE ve $\mathrm{R}^{2}$ performans kriterleri, gerçekleşen, YSA ile tahmin edilen ve saha denkleminden elde edilen PPV değerlerinden hesaplanmıştır. Gecikme başına kullanılan en fazla patlayıcı madde miktarı ve ölçekli mesafenin, en yüksek parçacık hızı üzerindeki duyarlılık analizi de belirlenmiştir. Sonuçta, saha denkleminden hesaplanan ve YSA modelinden tahmin edilen titreşim verileri, gerçekleşen titreşim verileri ile karşılaştırıldığında, YSA modeli ile elde edilen değerlerin daha yüksek korelasyona sahip olduğu görülmüştür.

Anahtar Kelimeler: Yapay sinir ă̆ l, titreşim, patlatma, taş ocağı, duyarlılık analizi, MAPE, RMSE, $R^{2}$.

\section{Introduction}

The further development of both explosives and ignition systems has led to significant advances in the mining and construction sectors. Blasting operations are one of the most important and economical procedures at the beginning of the methods applied especially in mines and quarries. However, blasting applications have some negative effects such as vibration and air shock. Feeling the earthquake-like effects from long distances causes psychological disturbances on humans and animals and some environmental problems. For this reason, measuring the vibration level continuously and being able to predict it using these data is very important in evaluating the design of blasting operations. Ground vibrations that occur during blasting are dependent on controllable parameters such as hole diameter, hole length, charge per delay, total charge, stemming, slice thickness, distance between holes, and uncontrollable parameters such as rock properties, environmental and geological conditions. Ground vibration is measured in $\mathrm{mm} / \mathrm{sec}$ or inch / $\mathrm{sec}$ and is defined by peak particle velocity (PPV), which is the highest velocity at which a particle moves through the ground relative to its initial stationary state.

Since the number of parameters affecting ground vibration is high, estimating the PPV value with artificial neural network (ANN) is now frequently applied instead of experimental methods in pre-determination. ANN is considered as one of the smart tools in complex structured calculations. ANN learns and is trained from examples

\footnotetext{
* Corresponding author.

E-mail address: sercins@cumhuriyet.edu.tr (S. Ercins)

Received o3 August 2021; Received in revised form 17 October 2021; Accepted 10 December 2021
} 
previously taught, described. The appropriately trained network can be used to predict or decide on known instances of a problem and subsequent events about it. However, the network has no ability to explain how it makes these decisions.

Some of the studies carried out using neural networks are given below.

Özyurt has developed a model that determines the most suitable production method for a mineral deposit [1].

Khandelwal and Singh estimated the excessive air pressure based on distance and sound pressure level using the artificial neural network. They compared their findings with the USBM and MVRA equations. As a result, they found better results with ANN compared to USBM and MVRA predictive values [2].

Liu modeled the change in methane concentration [3].

Özer et al. modeled the blasting and environmental outcomes [4].

Tawadrous used ANN for blasting design and achieved very good results [5].

Khandelwal and Singh estimated the PPV by taking into account the measurement distance and the amount of explosive per delay with ANN. They compared their findings with commonly used vibration estimation equations. They found that ANN estimation obtained much more effective results compared to vibration prediction equations [6].

Khandelwal and Singh conducted studies on blast vibration and frequency by using blast design and parameters in ANN. He compared his results with multivariate regression analysis [7].

Mohamed developed and successfully implemented an ANN model for the prediction and control of blast vibration in the limestone quarry [8].

In this study, the highest particle velocities resulting from blasting applications in a quarry were recorded and an ANN model was created with these values. The estimated values obtained from $\mathrm{ANN}$ and the realized velocity values were compared. In addition, in determining the performance of the network, the results obtained from mean absolute percentage error (MAPE), root mean square error (RMSE) and $\mathrm{R}^{2}$ performance criteria were interpreted.

\section{Artificial Neural Networks}

With the development of technology and computer infrastructure, the usability of numerical methods in solving complex problems has increased.

Thanks to the partnership of numerical methods with computers and increased computing power, a solution is reached without the need for assumptions and timeconsuming techniques [9].

Artificial neural network is a branch of artificial intelligence that can make decisions based on sample data, including expert systems and genetic algorithms. Information society has taken the place of the industrial society, especially with the artificial intelligence studies that gained momentum thanks to ANN [10]. ANN is an information processing system that imitates the structure and functions of our brain. ANN is a structure consisting of many neurons that can make many joints connected to each other in data processing. In the training of the neural network, a large number of input data is introduced to the network and the most appropriate output is processed according to the structure of the problem. It can recognize similarities when a new input data is presented to the neural network that predicts the most appropriate training and output model. [11].

\subsection{Artificial Neural Network Model}

ANN needs to be trained before making predictions about examples. A number of algorithms are available to perform this training. The most versatile and reliable one of these algorithms is the back propagation algorithm, which is also used in the solution of prediction problems. This algorithm provides a highly efficient learning procedure for neurons and thus error minimization is achieved [12].

Optimizing the weights with the back propagation of error information obtained from each new sequential process to the next sequential process is the main reason for the success of the algorithms. The most important backpropagation algorithms are Levenberg Marquadt (LM), Scaled Conjugate Reduction (SCG) and Bayes (BR) algorithms [13], [14].

In this study, Levenberg Marquadt backpropagation algorithm was run with Matlab program licensed at our university. The LM algorithm in the form of the sum of error squares has been developed specifically to work with loss functions. Here, the loss functions indicate the difference between the estimated values made by the model and the realized values. It is desirable that this difference is close to zero.

The back propagation algorithm in ANN consists of at least three layers as input layer, hidden layer and output layer. Each layer is made up of a series of basic processing units called neurons. Neurons in the input layer send their output as input to the neurons in the hidden layer. Neurons in the input layer send their output as input to neurons in the hidden layer. The connection between the hidden layer and the output layer is similar to this. Depending on the type of problem, the number of neurons in the hidden layer changes. The number of input and output neurons is the same as the number of input and output variables [11].

\section{Material and Method}

\subsection{Highest Particle Velocity Prediction}

The highest PPV, which is an important indicator in determining the damage caused by blasting applications; depends on scale distance, maximum amount of explosives used per delay, rock and environmental characteristics. There are many experimental approaches to estimating the highest particle velocity. Equation-1, which is the most accepted, used and developed to estimate the highest particle velocity depending on the scaled distance in the literature, is as follows [15].

$\mathrm{PPV}=\mathrm{k} *(\mathrm{SD})^{-\beta}$

PPV: Peak particle velocity $(\mathrm{mm} / \mathrm{sec})$

$\mathrm{k}$ : Ground transmission constant

SD: Scaled distance (m) 
$\beta$ : The damping coefficient of the rock (Geological constant)

The scaled distance is a value that takes into account the distance between the blasting zone and the measurement point and the highest amount of explosive used per delay and is calculated with Equation-2 [16].

$\mathrm{SD}=\mathrm{R} / \mathrm{W}^{0,5}$

SD: Scaled distance

$\mathrm{R}$ : Distance between blasting zone and measurement point (m)

W: Maximum amount of explosives used per delay $(\mathrm{kg})$

The distance between the blasting area and the point where the vibration measuring device is installed was measured and the scaled distance was determined using Equation 2. The average measurement distance of all explosions was determined as 267 meters.

\subsection{Geology of the Study Area and Blasting Data}

Crushed stone (limestone) is produced in the enterprise located near Kayapınar Village in Ulaş District of Sivas Province.

It is represented by gray, blackish colored, mediumthick bedded limestone in the Tecer Mountain region. Its thickness is variable and it looks like a level without lateral continuity. This limestone, which unconformably deposited on the ophiolite mixture, gained its present position as a result of the second transfer of ophiolites in the Eocene. The age range of Upper Maastrichtian Thanetian has been given to the unit. [17]

Information on 28 blasting applications measured and PPV values determined by vibration measuring device are given in Table 1.

Table 1. Information on blasting applications

\begin{tabular}{|c|c|c|}
\hline $\mathrm{W}$ & SD & PPV \\
\hline 52 & 37,17 & 5,691 \\
\hline 45 & 40,40 & 4,303 \\
\hline 52 & 37,03 & 5,107 \\
\hline 48 & 38,39 & 4,991 \\
\hline 50 & 38,33 & 4,994 \\
\hline 42 & 42,74 & 3,191 \\
\hline 45 & 35,93 & 4,587 \\
\hline 40 & 43,17 & 3,712 \\
\hline 45 & 37,86 & 3,218 \\
\hline 60 & 27,24 & 4,012 \\
\hline 50 & 40,31 & 3,413 \\
\hline 48 & 41,14 & 3,421 \\
\hline 60 & 29,31 & 8,000 \\
\hline 53 & 34,75 & 3,697 \\
\hline 40 & 40,79 & 3,925 \\
\hline 43 & 51,55 & 3,182 \\
\hline 48 & 44,46 & 3,318 \\
\hline 48 & 61,02 & 2,365 \\
\hline 51 & 46,02 & 2,925 \\
\hline 50 & 28,33 & 6,118 \\
\hline 40 & 47,65 & 2,718 \\
\hline 35 & 55,62 & 2,108 \\
\hline 38 & 45,08 & 3,081 \\
\hline 48 & 36,03 & 4,459 \\
\hline 52 & 28,22 & 5,877 \\
\hline 48 & 31,12 & 4,887 \\
\hline 45 & 28,74 & 5,504 \\
\hline 45 & 29,35 & 6,411 \\
\hline
\end{tabular}

Regression analysis was performed for the study area by using the data in Table 1 . The recommended field constant value to be used in particle velocity estimation for blasting applications to be carried out in the field was determined as $\mathrm{R}^{2}=0.71$. This value can be used to estimate the PPV value according to the scaled distance when the vibration measuring device is not used in blasting applications in the field.

\subsection{Network Structure Developed for PPV Prediction}

In this study, the vibration of a total of 28 explosion applications was recorded. 20 data were used for training of ANN model and obtaining field constants, 4 data for validation of ANN model and 4 data for testing. In the study aiming to estimate the highest particle velocity with the help of different explosion design parameters and related parameters such as measurement distance, PPV was used as the output parameter, and the maximum explosive amount per delay and scaled distance as the input parameter. In the training model initiated with the Levenberg Marquadt learning algorithm, network structure with $5,10,15$ and 20 neurons were tested. The results obtained for each number of neurons tested, it is presented as in Figures 2, 3, 4 and 5. In each of these trials, high correlation was observed with minimum error. The network structure with the highest correlation between the realized and predicted values and the lowest deviation rate was reached with an architecture of 10 neurons (Figure 1).

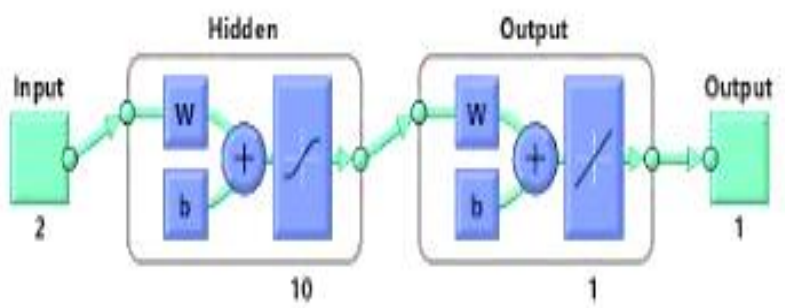

Figure 1. Artificial Neural Network model developed for PPV prediction

PPV outputs obtained from the network trained with the recorded PPV values are given in Table 2. The high correlation values between the estimated and realized results obtained with the model showed that when the vibration meter device cannot be used in field blasting applications, the ANN model can be used to estimate the value of the vibration velocity generated by the explosive used per delay at a certain distance.

The results in Figures 2, 3 and 4 belong to the network architectures of the training model with 5, 15 and 20 neurons.

As can be seen, in the training model using 10 neurons, values with higher correlation and less deviation between realized and predicted values were obtained compared to models using 5, 15 and 20 neurons. The relationships between realized and ANN predicted values are given in Figure 5. 
Table 2. PPV outputs from the realized and trained network

\begin{tabular}{|c|c|}
\hline $\begin{array}{l}\text { Realized } \\
\text { PPV }\end{array}$ & $\begin{array}{c}\text { Estimated PPV in ANN } \\
\text { model }\end{array}$ \\
\hline 5,691 & 4,982 \\
\hline 4,303 & 4,365 \\
\hline 5,107 & 4,929 \\
\hline 4,991 & 4,675 \\
\hline 4,994 & 4,955 \\
\hline 3,191 & 3,238 \\
\hline 4,587 & 4,083 \\
\hline 3,712 & 3,367 \\
\hline 3,218 & 3,670 \\
\hline 4,012 & 4,013 \\
\hline 3,413 & 3,529 \\
\hline 3,421 & 3,336 \\
\hline 8,000 & 7,994 \\
\hline 3,697 & 3,777 \\
\hline 3,925 & 3,763 \\
\hline 3,182 & 3,219 \\
\hline 3,318 & 3,234 \\
\hline 2,365 & 2,357 \\
\hline 2,925 & 2,933 \\
\hline 6,118 & 6,042 \\
\hline 2,718 & 3,561 \\
\hline 2,108 & 2,109 \\
\hline 3,081 & 3,084 \\
\hline 4,459 & 3,863 \\
\hline 5,877 & 6,106 \\
\hline 4,887 & 5,174 \\
\hline 5,504 & 5,495 \\
\hline 6,411 & 5,379 \\
\hline
\end{tabular}
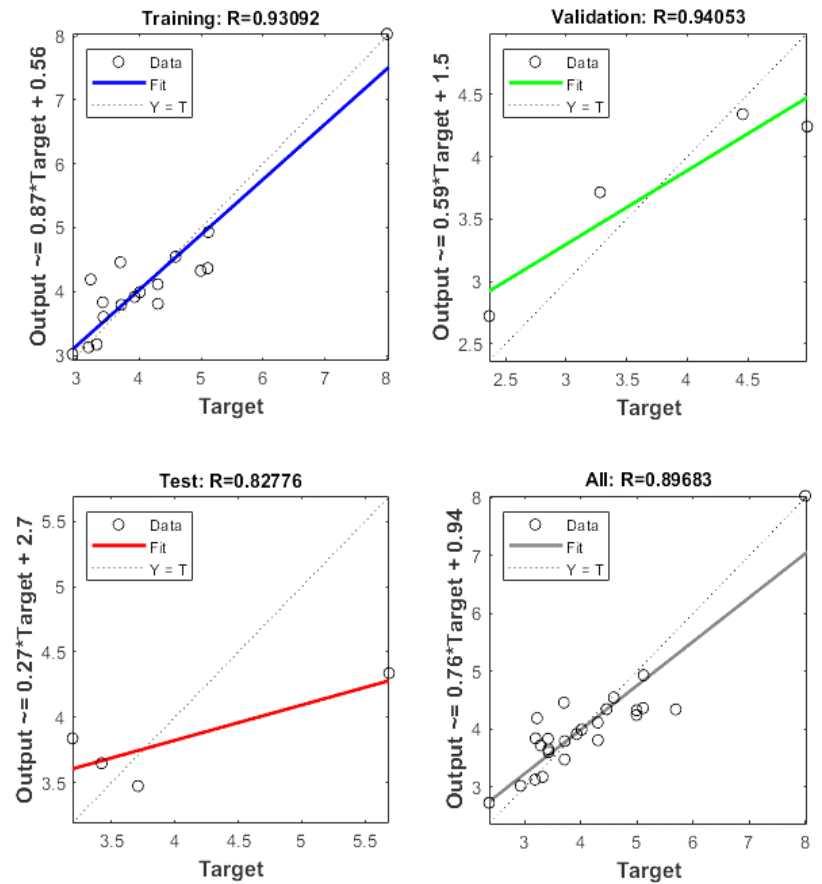

Figure 2. Relationships between actual and predicted values using 5 neurons
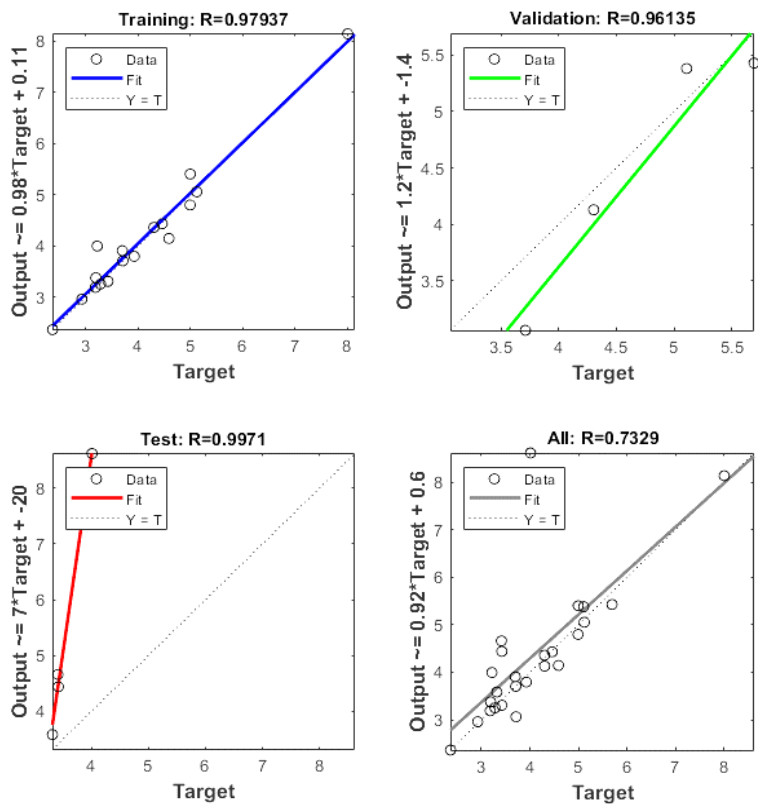

Figure 3. Relationships between actual and predicted values using 15 neurons
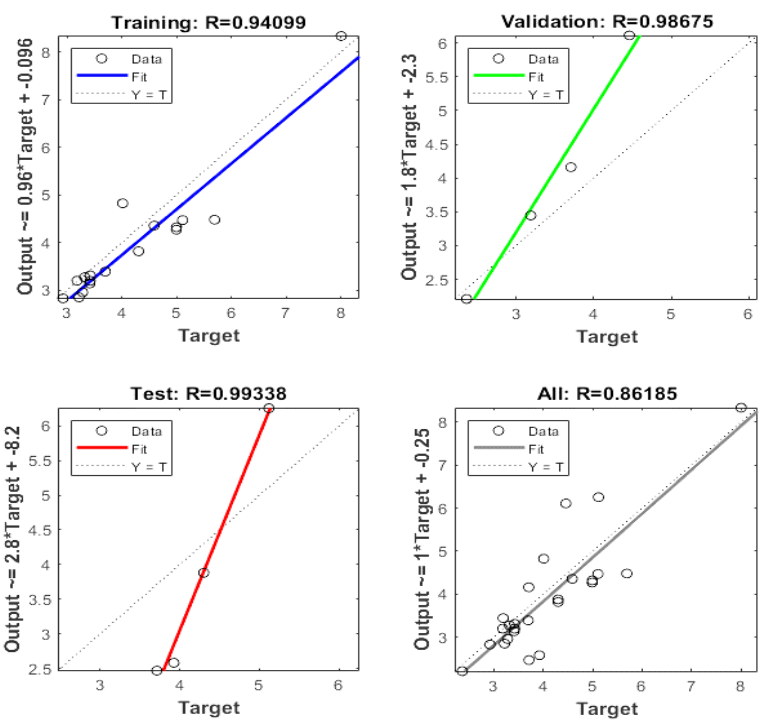

Figure 4. Relationships between actual and predicted values using 20 neurons
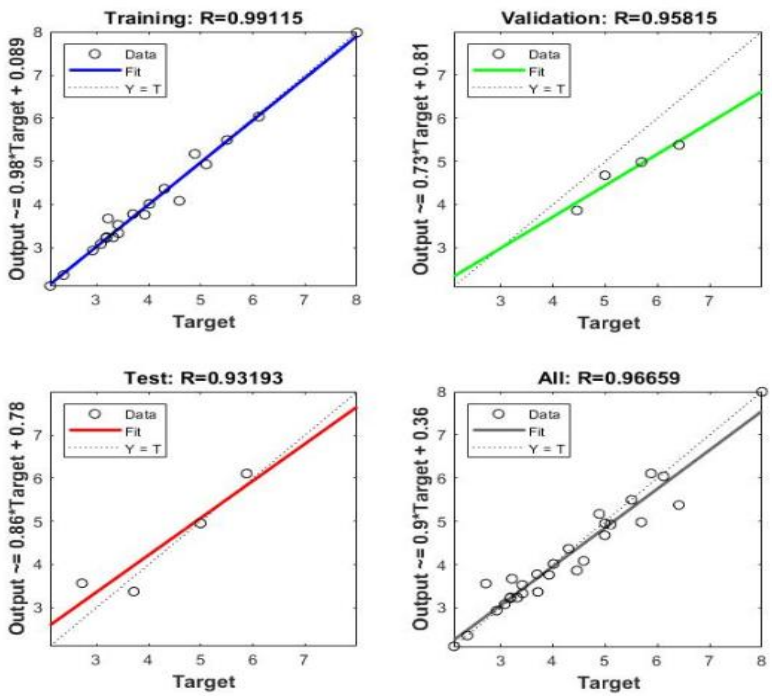

Figure 5. Relationships between realized and predicted values using 10 neurons 
In the graph of Training $(R=0.99115)$ in Figure 5, it is expressed by the dashed line $\mathrm{Y}=\mathrm{T}$, that the output value and its estimate should be equal. Here, the horizontal axis shows the realized PPV values and the vertical axis shows the estimated PPV values. In addition, the values obtained from the artificial neural network are shown with the blue line. As a result, it is desired that both values are as equal as possible to each other and that all points are collected on the dashed line. However, Validation and Test graphs can be interpreted in the same way. When looking at the graphs given in Figure 5, it is seen that the deviations between the realized and estimated values are the least and the modeling is successful.

The PPV values realized in the blasting applications in the field, the PPV values estimated by the ANN model and the PPV values obtained by the field equation are as in Table 3.

Table 3. Realized PPV and predicted values

\begin{tabular}{|c|c|c|}
\hline $\begin{array}{l}\text { Realized } \\
\text { PPV }\end{array}$ & $\begin{array}{l}\text { Estimated PPV in } \\
\text { ANN model }\end{array}$ & $\begin{array}{l}\text { PPV calculated } \\
\text { with the field } \\
\text { equation }\end{array}$ \\
\hline 5,691 & 4,982 & 4,221 \\
\hline 4,303 & 4,365 & 3,797 \\
\hline 5,107 & 4,929 & 4,241 \\
\hline 4,991 & 4,675 & 4,051 \\
\hline 4,994 & 4,955 & 4,059 \\
\hline 3,191 & 3,238 & 3,535 \\
\hline 4,587 & 4,083 & 4,407 \\
\hline 3,712 & 3,367 & 3,490 \\
\hline 3,218 & 3,670 & 4,124 \\
\hline 4,012 & 4,013 & 6,266 \\
\hline 3,413 & 3,529 & 3,808 \\
\hline 3,421 & 3,336 & 3,710 \\
\hline 8,000 & 7,994 & 5,709 \\
\hline 3,697 & 3,777 & 4,598 \\
\hline 3,925 & 3,763 & 3,751 \\
\hline 3,182 & 3,219 & 2,785 \\
\hline 3,318 & 3,234 & 3,362 \\
\hline 2,365 & 2,357 & 2,248 \\
\hline 2,925 & 2,933 & 3,218 \\
\hline 6,118 & 6,042 & 5,961 \\
\hline 2,718 & 3,561 & 3,078 \\
\hline 2,108 & 2,109 & 2,529 \\
\hline 3,081 & 3,084 & 3,303 \\
\hline 4,459 & 3,863 & 4,392 \\
\hline 5,877 & 6,106 & 5,991 \\
\hline 4,887 & 5,174 & 5,290 \\
\hline 5,504 & 5,495 & 5,853 \\
\hline 6,411 & 5,379 & 5,699 \\
\hline
\end{tabular}

When Table 3 is examined, it is seen that the ANN model gives more successful results in the estimation of vibration propagation in PPV estimation determined according to the scaled distance and the maximum amount of explosives used per delay.

Approaches developed to predict PPV have been widely used since the 1960s. However, instead of these traditional approaches in PPV estimation, more effective results can now be obtained with ANN developed with today's modern information and technologies.

Uyar G., and Aksoy C. [18] stated that the traditional hypotheses proposed in the criteria of USBM RI 8507 [15] in PPV estimation should be abandoned in favor of modern blast vibration analyzes based on modern scientific approach and technology, taking into account today's changing conditions.

PPV values obtained from ANN model and field equation were compared against PPV values measured during blasting applications. In the comparison, the main performance criterion $\mathrm{R}^{2}$, mean absolute percentage error (MAPE) and root mean square error (RMSE) error criteria values were calculated and presented in Table- 4 .

MAPE is a very important evaluation criterion in evaluating the performance of the network created. According to the literature, if the MAPE value is below $10 \%$, it means that the measured performance value is high [19].

RMSE is another criterion used in determining the error rate between realized and predicted values. The fact that its value is close to zero means that the created model is so close to perfection.

The $\mathrm{R}^{2}$ criterion is widely used to show the relationship between realized values and estimated values. If its value is close to 1 , it means that the accordance is close to perfect.

Table 4. Performance evaluations of vibration measurement results

\begin{tabular}{|l|c|c|}
\hline $\begin{array}{l}\text { Error } \\
\text { Criteria }\end{array}$ & $\begin{array}{c}\text { Realized PPV- } \\
\text { Estimated PPV in } \\
\text { ANN model }\end{array}$ & $\begin{array}{c}\text { Realized PPV-PPV } \\
\text { calculated with the } \\
\text { field equation }\end{array}$ \\
\hline MAPE & 0,053 & 0,134 \\
\hline RMSE & 0,356 & 0,819 \\
\hline $\mathrm{R}^{2}$ & 0,930 & 0,630 \\
\hline
\end{tabular}

When Table 4 is examined, it is seen that the developed ANN model gives better results than the field equation.

\section{Sensitivity Analysis}

Sensitivity analysis is a method that examines the effects of the change in the input parameters on the optimal solution parameter in the linear programming model. In this study, the maximum amount of explosive per delay and scaled distance were used as input parameters, while the highest particle velocity value was used as output parameter. [20].

Sensitivity analysis equation is given in Equation-3

$\mathrm{R}_{\mathrm{ji}}=\frac{\sum_{\mathrm{k}=1}^{\mathrm{m}}\left(\mathrm{X}_{\mathrm{ik}}{ }^{*} \mathrm{X}_{\mathrm{jk}}\right)}{\sqrt{\sum_{\mathrm{k}=1}^{\mathrm{m}} \mathrm{X}_{\mathrm{ik}}^{2} \sum_{\mathrm{k}=1}^{\mathrm{m}} \mathrm{X}_{\mathrm{jk}}^{2}}}$

Xi-1: Maximum amount of explosives used per delay $\mathrm{Xi}-2$ : Scaled distance

$\mathrm{Xj}$ : Highest particle velocity

The effect of each input parameter on the highest particle velocity is shown in Figure 6. 


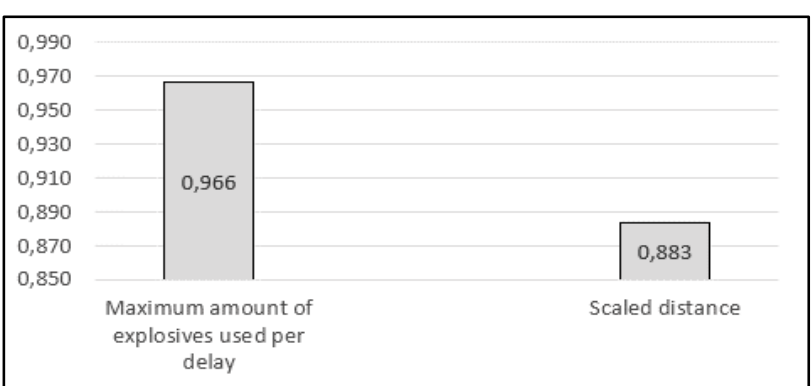

Figure 6. Sensitivity analysis showing the effect of input parameters on peak particle velocity

\section{Conclusions}

In this study, an artificial neural network model has been developed by using the ground vibration data measured from the blasting applications performed in the quarry. Evaluation and estimation of PPV data obtained from this model, measurement of performance of prediction models and sensitivity analysis were performed. In addition, the PPV values calculated from the field equation were compared with the realized and estimated PPV values.

Of the 28 recorded blasting applications, 20 were used in the training of the ANN model, 4 were used in the verification of the model and 4 were used in the testing of the model. The correlation between the realized vibration values and the training data obtained from the trained model was determined as 0.99115, the verification correlation as 0.95815 and the test correlation as 0.93193 . The total correlation value including the training, verification and test data between the vibration values realized and the vibration data estimated from the ANN was determined as 0.96659 . These results show that there is a very high correlation between realized and estimated PPV values with ANN.

The results of the performance criteria between the PPV values measured in the field and the PPV values estimated from the model and calculated from the field equation are given in Table 4. According to these results, the performance value (MAPE) of the ANN, which is desired to be below $10 \%$, was determined as $5.3 \%$ and the performance value (MAPE) of the field equation was determined as $13.4 \%$. The error rate (RMSE) of ANN data was determined as 0.356 , and the error rate (RMSE) of the data obtained from the field equation was determined as 0.819. The correlation level $\left(\mathrm{R}^{2}\right)$ between realized and predicted PPV values with ANN was 93\%, and the correlation level $\left(\mathrm{R}^{2}\right)$ between realized PPV values obtained from the field equation was $63 \%$. All these data obtained showed that the ANN model produced more effective results than the field equation.

The effects of W and SD on PPV were examined by sensitivity analysis. In the results, it was determined that the maximum amount of explosive used per delay was $96.6 \%$ and the scaled distance was $88.3 \%$ effective on PPV.

In the light of the obtained results, it was seen that the model created with artificial neural network represented the field better. In blasting applications where vibration measurement cannot be taken, it has been revealed that the ANN model is a very powerful alternative in predicting the value of the vibration velocity at a certain distance with the explosive material used per delay. In addition, by adding the next blast data to the network, it will be provided to create a model that learns better and can predict vibration even better.

\section{Declaration}

The authors declare that the ethics committee approval is not required for this study.

\section{References}

[1] Özyurt, M.C. (2018). The Investigation of Using Artificial Neural Networks and Game Theory on Underground Mining Method Selection. (Doctoral dissertation, Istanbul University).

[2] Khandelwal, M., \& Singh, T. N. (2005). Prediction of blast induced air overpressure in opencast mine. Noise \& Vibration Worldwide, 36(2), 7-16.

[3] Liu, Q. L., \& Li, X. C. (2014). Modeling and evaluation of the safety control capability of coal mine based on system safety. Journal of cleaner production, 84, 797-802.

[4] Ozer, U., Karadogan, A., Ozyurt, M. C., Sahinoglu, U. K., \& Sertabipoglu, Z. (2019). Environmentally sensitive blasting design based on risk analysis by using artificial neural networks. Arabian Journal of Geosciences, 12(2), 60.

[5] Tawadrous, A. (2006). Evaluation of artificial neural networks as a reliable tool in blast design. In proceedings of the annual conference on explosives and blasting technique (Vol. 32, No. 1, p. 71). ISEE; 1999.

[6] Khandelwal, M., \& Singh, T. N. (2007). Evaluation of blastinduced ground vibration predictors. Soil Dynamics and Earthquake Engineering, 27(2), 116-125.

[7] Khandelwal, M., \& Singh, T. N. (2006). Prediction of blast induced ground vibrations and frequency in opencast mine: a neural network approach. Journal of sound and vibration, 289(4-5), 711-725.

[8] Mohamed, M. T. (2009). Artificial neural network for prediction and control of blasting vibrations in Assiut (Egypt) limestone quarry. International Journal of Rock Mechanics and Mining Sciences, 46(2), 426-431..

[9] Chapra, S.C., Canale, R.P. (2015). Software and Numerical Methods for Engineers with Programming Applications. Literature Publishing, Translators: Hasan Heperkan, Uğur Kesgin, Istanbul, Turkey.

[10] Öztemel, E. (2016), Artificial Neural Networks, (4th Edition). Daisy Publishing, Istanbul, Turkey.

[11] Khandelwal, M., \& Singh, T. N. (2009). Prediction of blastinduced ground vibration using artificial neural network. International Journal of Rock Mechanics and Mining Sciences, 46(7), 1214-1222.

[12] Meulenkamp, F., \& Grima, M. A. (1999). Application of neural networks for the prediction of the unconfined compressive strength (UCS) from Equotip hardness. International Journal of rock mechanics and mining sciences, 36(1), 29-39.

[13] Lv, C., Xing, Y., Zhang, J., Na, X., Li, Y., Liu, T., ... \& Wang, F. Y. (2017). Levenberg-Marquardt backpropagation training of multilayer neural networks for state estimation of a safety-critical cyber-physical system. IEEE Transactions on Industrial Informatics, 14(8), 34363446.

[14] Baghirli, O. (2015). Comparison of Lavenberg Marquardt, Scaled Conjugate Gradient and Bayes Regularization Backpropagation Algorithms for Multistep Ahead Wind Speed Forecasting Using Multilayer Perceptron Feedforward Neural Network. (Master dissertation, Uppsala University) 
[15] Siskind, D. E. (1980). Structure response and damage produced by ground vibration from surface mine blasting (Vol. 8507). US Department of the Interior, Bureau of Mines.

[16] Dowding, C. H. (1985). Blast Vibration Monitoring and Control, Prentice-Hall, 297s.

[17] Inan, S., Öztürk, A., \& Gürsoy, H. (1993). Stratigraphy of Ulas-Sincan (Sivas) area. Turkish Journal of Earth Sciences, 2, 1-15.

[18] Uyar, G. G., \& Aksoy, C. O. (2019). Comparative review and interpretation of the conventional and new methods in blast vibration analyses. Geomechanics and Engineering, $18(5), 545-554$.
[19] Yadav, V., \& Nath, S. (2017). Forecasting of PM 10 using autoregressive models and exponential smoothing technique. Asian Journal of Water, Environment and Pollution, 14(4), 109-113.

[20] Duvall, W. I. (1963). Vibrations from instantaneous and Millisecond-delayed quarry blasts (No. 6151). US, Department of the Interior, Bureau of Mines. 